\title{
Um novo amanhecer através da arteterapia... Resgatando relacionamentos, após a mastectomia
}

\author{
A new dawn through arttherapy... \\ relationships after a mastectomy
}

DOI: $10.46814 /$ lajdv2n5-006

Recebimento dos originais: 10/07/2020

Aceitação para publicação: 30/08/2020

\author{
Maria Carolina Monteiro Machado de Souza Brando \\ Psicologa pela PUCSP \\ Especialização em Psico-oncologia e Arteterapia pelo Instituto Sedes Sapientiae \\ Instituto Sedes Sapientiae - Rua Ministro Godoi, 1484 São Paulo, SP - CEP 05015-900 \\ E-mail: sedes@ sedes.org.br
}

\section{RESUMO}

O objetivo deste trabalho visou o relacionamento conjugal de mulheres mastectomizadas.

Levando em conta os aspectos socioculturais brasileiros, observamos que mulheres mastectomizadas apresentavam muitos problemas de relacionamento com seus companheiros quanto à sexualidade, intimidade e imagem corporal, especialmente em classes sociais mais baixas.

Foi elaborado um workshop de arteterapia onde foram convidados seus maridos ou companheiros. Foi um trabalho piloto que implantamos através de uma ONG que trabalhava com a prevenção do câncer de mama na América Latina.

Trabalhamos com um grupo de classe social baixa em um cidade litorânea do Estado de São Paulo. No início, os homens apresentaram certa resistência. Entretanto, um dos pontos culminantes do workshop foi o depoimento dos maridos/companheiros que participaram do evento. Participaram ativamente com suas esposas e apresentaram seus trabalhos ao grupo de maneira afetiva e emocional. As mulheres mostraram-se extremamente surpresas com essa reação masculina.

Trabalhamos através da música, da expressão corporal, histórias, desenhos, além de um processo de confraternização.

Através do processo criativo, conseguimos atingir nossa meta. Os homens tiveram a oportunidade de se expressarem através das imagens, autentica e espontaneamente, e com o tempo essa experiência pode leva-los a uma melhor visão de si mesmos, assim como uma provável reparação e transformação emocional, além de ajudarem suas esposas na recuperação após um câncer de mama. Utilizamos também elementos informativos, introduzindo pela primeira vez uma visão dos sentimentos femininos e masculinos após o diagnóstico de câncer de mama.

Obtivemos um resultado bastante positivo ao recebermos pedidos dos participantes para que implantássemos um novo workshop dando continuidade ao trabalho começado.

O processo criativo tem se mostrado muito eficiente em trabalhos dentro da área da saúde. Sendo a comunicação de maneira simbólica, a arte facilita novos entendimentos e insights. Ajuda na resolução de conflitos, solução de problemas e formulação de novas percepções que o conduzirão a mudanças positivas, crescimento e cura.

Palavras-chave: câncer de mama, relacionamento conjugal, arteterapia. 


\section{ABSTRACT}

The purpose of the project was to work the relationships of the women after a mastectomy, through arttherapy.

In addition to the socialcurtural brazilian context, we observed problems on sexuality, body image and intimate relationships in women after mastectomy, specially in lower classes.

We were asked to help women after mastectomy of a small town of São Paulo, who attended to a public health service.

We planned a art workshop and we asked them to invite their husband or closest friend.

Besides the art project, we introduced to that group for the first time a vison of the feelings women and men have after a breast cancer diagnosis. Issue that had never been spoken before.

We worked with music body exercises, stories, drawings and we also offered a confraternization meal.

It was amazing listen to some men who attended to the workshop. They participated with their wives and they talked to the group in a touched way. The women were surprised with those reactions. They asked for another workshop to continue this project.

We had a group of social low classe. The men who participated showed some resistance at the beginning. But through the art proposal we could get our goal. They had an opportunity to express themselves imaginatively, authentically and spontaneously, and over time these experience can lead them to personal fulfillment, emotional reparation and transformation.

The creative process can be health-enhancing and growth-producing experience.

Through art the communication is symbolic. In a psychotherapy, with drawings, paintings and other art expressions art can facilitate new understandings and insights. It can help resolve conflicts, solve problems and formulate new perceptions that in turn lead to positive changes, growth and healing.

Keywords: breast cancer, marital relationship, arttherapy.

\section{INTRODUÇÃO}

A Arteterapia tem o componente simbólico de arte para facilitar a expressão de sentimentos fortes e muitas vezes conflitantes, os quais podem ser considerados muito difíceis para serem colocados em palavras. A Arteterapia facilita a mobilização de recursos previamente não revelados acessando o inconsciente. Os resultados da arteterapia nos últimos anos foram a melhora na comunicação, desenvolvimento de atitudes criativas pelos pacientes a respeito de suas circunstâncias, aumento do senso de controle, ampliação das capacidades expressivas, aumento de insights a respeito dos comportamentos dos próprios pacientes, relatos sobre a imagem corporal, melhora na autoestima, melhora na qualidade de vida, catarse de assuntos emotivos, melhora na habilidade de confrontar questões existenciais e aliviar sofrimento espiritual, desenvolvimento de estratégias positivas de enfrentamento, redução de experiências e relatos de dor física.

\section{OBJETIVO}

O objetivo do projeto foi melhorar os relacionamentos das mulheres mastectomizadas. 
Levando em consideração os aspectos socioculturais brasileiros, observamos que mulheres mastectomizadas apresentavam muitos problemas de relacionamento com seus companheiros quanto à sexualidade, intimidade e imagem corporal, especialmente em classes sociais mais baixas.

\section{POPULAÇÃO}

60 mulheres e 15 homens de uma cidade litorânea do Estado de São Paulo, participantes de um grupo de apoio filiado à ONG AMERICAmama, coalizão de grupos voluntários no combate do câncer de mama na América Latina.

\section{METODO}

Workshop de Arteterapia, sendo um projeto piloto a ser implantado na instituição.

Trabalhamos com música, conscientização corporal, histórias, desenhos, informações sobre os sentimentos de ambos após um diagnóstico de câncer e finalizamos com uma confraternização.

Aquecimento

Iniciamos com exercícios ao ar livre para a introdução dos participantes, relaxando-os para o início da nossa programação. Durante estes exercícios introduzimos conscientização corporal.

\section{Informação}

Além do projeto artístico, trouxemos para o grupo informação sobre como o câncer pode estressar a família e/ou a vida conjugal. Foi também apresentada pela primeira vez para eles a diferença entre os sentimentos da mulher e do homem após receberem um diagnóstico de câncer.

Arteterapia através da história e do desenho

Foi contada a história de um girino e de uma lagarta que se apaixonaram e prometeram um ao outro nunc mudarem. Mas eles se transformam em sapo e borboleta.

O objetivo era trabalhar a modificação corporal e o relacionamento com a pessoa amada.

A história foi interrompida no momento da mudança e eles foram convidados a continuarem a história da maneira que quisessem, através de desenhos.

Apesar da resistência inicial, os homens surpreenderam a todos com seus trabalhos e depoimentos emocionados.

As mulheres ficaram emocionadas e disseram que não poderiam imaginar este tipo de reação.

\section{RESULTADOS}

Através do processo artístico atingimos a nossa meta.

Foi pedido pelos participantes que montássemos uma continuação deste workshop. Eles tiveram a oportunidade de se expressarem através das imagens, de maneira espontânea e autêntica. 
Esta experiência poderá leva-los a melhor conhecimento de si mesmos e ajuda-los no processo de restabelecimento de suas esposas ou companheiras.

O PROCESSO CRIATIVO PODE MELHORAR A SAÚDE E O BEM ESTAR... 